\title{
Angiogenesis as a prognostic factor of pathological stage IA lung adenocarcinoma: Developing an angiogenic score
}

Karol De Aguiar-Quevedo ${ }^{*}$, Amparo Ruiz Saurí2, José Cerón Navarro ${ }^{3}$, Carlos Jordá Aragón ${ }^{3}$, Julia Cruz Mojarrieta ${ }^{4}$, Nuria Mancheño Franch $^{5}$, Miguel Arrarás Martínez ${ }^{1}$, Encarnación Martínez Pérez ${ }^{6}$, Francisco Vera Sempere ${ }^{7}$ and Juan Carlos Peñalver Cuesta ${ }^{8}$

${ }^{1}$ Thoracic Surgery Department, Valencian Institute of Oncology, Valencia, Spain

${ }^{2}$ Pathology Anatomy Department, Valencia University, Valencia, Spain

${ }^{3}$ Thoracic Surgery Department, La Fe university and polytechnic hospital, Valencia, Spain

${ }^{4}$ Pathology Anatomy Department, Valencian Institute of Oncology, Valencia, Spain

${ }^{5}$ Pathology Anatomy Department, La Fe university and polytechnic hospital, Valencia, Spain

${ }^{6}$ Pneumology Department, Valencian Institute of Oncology, Valencia, Spain

${ }^{7}$ Chief of Pathology Anatomy Department, La Fe university and polytechnic hospital, Valencia, Spain

${ }^{8}$ Chief of Thoracic Surgery Department, Valencian Institute of Oncology, Valencia, Spain

\begin{abstract}
Purpose: This work was designed to correlate the expression of markers of tumoral angiogenesis in lung adenocarcinoma as a prognostic factor and create a predictive model with these factors.

Patients and methods: A clinical, observational and analytical research study was undertaken. This work sought to describe and compare prognosis value of angiogenic markers of 119 resected patients, classified as pathological stage IA. The tumour angiogenesis analysis was performed, the survival and predictive value of microvascular density (MVD) expression with tumoral relapse and survival were evaluated. Finally, an accurate score, "Angioscore", was calculated by combining different markers.

Results: Low MVD-CD34 is associated with a worse disease-free survival (DFS) and cancer specific survival (CSS). High MVD-CD31 is significantly related to reduce DFS and CSS. High MVC-CD105 is associated with worse clinical outcomes. The predictive capacity of these angiogenic markers independently it is not exact. The "Angioscore" is able to provide better information about patient prognosis $(74.8 \%$ and $73.7 \%)$. Two groups were obtained with the risk value obtained by "Angioscore". A significant difference in the prognosis of both groups was accomplished ( $p<0.001)$. Being in the multivariate analysis the only independent prognostic factor in patients with lung ADC in stage IA of this series.
\end{abstract}

Conclusion: Tumour angiogenesis is a prognostic factor in early stage lung adenocarcinoma, the analysis of this factor being more accurate using a score, with great predictive value for the prognosis of patients.

\section{Introduction}

Tumours, like normal tissues, need a constant supply of nutrients and $\mathrm{O}_{2}$, as well as the elimination of metabolic residue and $\mathrm{CO}_{2}$, which is why they induce angiogenesis. Former research works have demonstrated that the degree of intratumoural vascularisation is a factor with a significant independent prognostic value for the recurrence and survival of some tumour-related diseases, including lung cancer (LC) [1-3].

According to world data that have recently become available, LC is the most frequently diagnosed neoplasia that causes most deaths worldwide. Despite recent advances, this disease still has a bad prognosis with survival below $19 \%[1,4,5]$.

Adenocarcinoma (ADC) is the most frequent histological subtype among non-small lung cancers (NSLC) and is also the most variable and heterogeneous form of LC. This seems to be one of the determining reasons why different clinical behaviours appear in patients with the same tumour stage. Thus, it has become a relevant focal point to investigate different prognostic factors to classic TNM in an attempt to improve directed therapies and survival [6].
Prognostic factors aim to predict the probability of an event occurring in cancer, mortality or relapse. However, a single factor is not usually helpful for this purpose. Therefore, it is necessary to create predictive models or risk scores that include a combination of prognostic factors, and to more precisely approach the probability of the event under study.

This work was designed to investigate and correlate the expression of markers of tumoural angiogenesis in lung ADC as a prognostic factor in resected patients classified as pathological stage IA according to the 8th edition of the TNM classification to establish risk groups, and to create a new score that better stratifies patients with stage IA lung ADC.

${ }^{\star}$ Correspondence to: Karol De Aguiar Quevedo, Direction: Street Profesor Beltrán Báguena, nº 8, 46009 Valencia, Spain, E-mail: karol.deaguiar@gmail.com

Key words: angiogenesis, lung cancer, CD34, CD31, CD105, lung adenocarcinoma Received: March 30, 2020; Accepted: April 13, 2020; Published: April 16, 2020 


\section{Materials and method}

A retrospective clinical, analytical and observational research project was carried out with cases using medical records from two hospitals. The included patients had been diagnosed with pathologic stage IA lung ADC according to the 8th edition of the TNM classification. They had undergone surgical resection in the first hospital between 1 January 1990 and 31 December 2007, and during the period from 1 November 2008 to 31 January 2012 in the second hospital.

After revising samples, the patients whose pathological anatomy differed from ADC, those who were on some form of neoadjuvant therapy and any patient with previous malignant neoplasia were excluded from the study. The final study cohort included 119 patients.

The follow-up period started with surgery and continued until the patient relapsed or died. It continued until the study ended on 1 January 2018 for those who survived. Follow- up was carried out during the external consultations held in both hospitals by means of anamnesis and an image scan.

The study was conducted in accordance with the principles of the Declaration of Helsinki and national legal regulations. The protocol was approved by our Hospital's Ethical Research Committee (EC).

Tumour tissue samples were analysed by ruling out those areas morphologically altered by atelectasis or lung emphysema. Conventional histological techniques, previously published by our group, were used for the morphological study [7].

In order to evaluate angiogenesis, endothelial markers CD31 (monoclonal antibody, $\mathrm{DAKO}^{\circ}$, Glostrup, Denmark), CD34 (monoclonal antibody, DAKO ${ }^{\circ}$, Glostrup, Denmark) and CD105 (monoclonal antibody, $\mathrm{DAKO}^{\circ}$, Glostrup, Denmark) were employed.

All preparations were scanned and microphotograghs by a Pannoramic SCAN $1501.17^{\circ}$ processor (3DHISTECH Ltd, Hungary) and the Pannoramic Viewer ${ }^{\circ}$ software 1.15.3, respectively. Six areas from each preparation were randomly selected and microphotographed at the 20X objective. The included area was $0.32 \mathrm{~mm}^{2}$ to obtain a total of 1.92 $\mathrm{mm}^{2}$. Samples were analysed by an experienced pathologist. The ProPlus 6.1 Media- Cybernetics ${ }^{\circledR}$ (USA) imaging system was used to study tumour angiogenesis by counting microvessels per $\mathrm{mm}^{2}$ (MVD). The study variables were age, gender, smoking, surgical excision extension. The presence (from 5\%) or absence of each histological component was evaluated, as were tumour size, invasion size and pathologic TNM. Vascular (IV) and lymphatic (IL) microscopic invasions were defined as absent or present. Finally, the nuclear grade was analysed according to the criteria of Barletta et al. [8].

Tumour recurrence was evaluated according to the patients' outcomes. Its location was recorded as local-regional recurrence, this being the presence of tumoral recurrence in the primary tumour location, and was even taken as mediastinal adenopathies being present, distant relapse, presence of systemic metastases. The patients' condition was designated as living, exitus by LC and exitus due to others cause than LC..

\section{Statistical analysis}

The statistical analysis was performed with version 22 of SPSS Windows ${ }^{\oplus}$. The Kaplan-Meier method was used to calculate diseasefree survival (DFS) and cancer-specific survival (CSS). The log-rank test was applied to compare the survival curves according to the different prognostic factors. The continuous variables were previously dichotomised by seeking the optimum cut-off point. Determining the predictive value of microvascular density (MVD) expression when tumoural relapse or death by cancer appeared was done by using the functions curves with receptor operation characteristics (ROC).

A score was calculated by combining different markers to obtain the most significant results. The angiogenesis markers were included in a Cox proportional hazard model for the multivariate analyses, which was utilised to obtain the regression coefficient. It was finally used to create the score, named the "Angioscore". The predictive "Angioscore" value was verified with the ROC curve for tumoural relapse and for death by ADC. The ROC curves for each tumoural relapse type were also analysed. An optimum cut-off point was sought, like the other variables, and two groups were created: low "Angioscore" and high "Angioscore". The survival curves were analysed by the Kaplan-Meier method and were compared to the log-rank method.

The clinical and pathological variables that were significant in a previous study were analysed in a multivariate forward stepwise Cox proportional hazard model, along with the "Angioscore", to establish the independent prognostic factors. The hazard ratio (HR) was reported with a $95 \%$ confidence interval $(95 \% \mathrm{CI})$. Statistical significance was defined when the $\mathrm{p}$ value was $\leq 0.05$.

\section{Results}

The clinical and pathological characteristics are shown in Table 1. CD34 and CD31 were positive in the whole sample. When 115 lung ADC samples were analysed, CD105 was found to be positive in $87.8 \%$ of the cases (101).

MVD was categorised at an optimum cut-off point of three markers, with 192 vessels $/ \mathrm{mm}^{2}$ for CD34, and 339 vessels $/ \mathrm{mm}^{2}$ for CD31 which coincided with the mean. CD105 also coincided with the mean of 243 vessels $/ \mathrm{mm}^{2}$. A survival analysis was done, and a comparison was made of the curves between the "low MVD" and the "high MVD" of each marker, which were compared by the log-rank method (Figure 1).

To evaluate the predictive capacity of each angiogenesis marker for prognosis purposes, the area under the curve (AUC) was analysed by a ROC analysis for tumoural relapse and death by cancer. This predictive capacity was significant only for the MVD with CD105, but it was not very exact (Figure 2).

The "Angioscore" was created using the following equation with the regression coefficients shown in Table 2. ANGIOSCORE $=\left(\mathrm{CD} 34^{\star}-1\right.$. $256)+(\mathrm{CD} 31 * 1.705)+(\mathrm{CD} 105 * 1.300)$

When the "Angioscore" score for each patient was calculated, the risk median was set at 0.45 with a minimum value of -1.26 and a maximum one of 3.01. Its predictive value was analysed with the ROC curve. The results are presented in Figures $3 \mathrm{~A}$ and $3 \mathrm{~B}$, with a statistically significant predictive value higher than that obtained separately with each marker. Table 3 also shows the ROC curve analysis of the "Angioscore" as a predictor of brain- (Figure 3C), lung(Figure 3D), and loco-regional type relapses, and of other less frequent metastases, which were grouped. Except in these last cases, the results were significant.

Two groups were obtained with the risk value obtained by the "Angioscore": "low Angioscore" and "high Angioscore". In both these groups, the Kaplan-Meier method was applied to analyse DFS and CSS. 
A

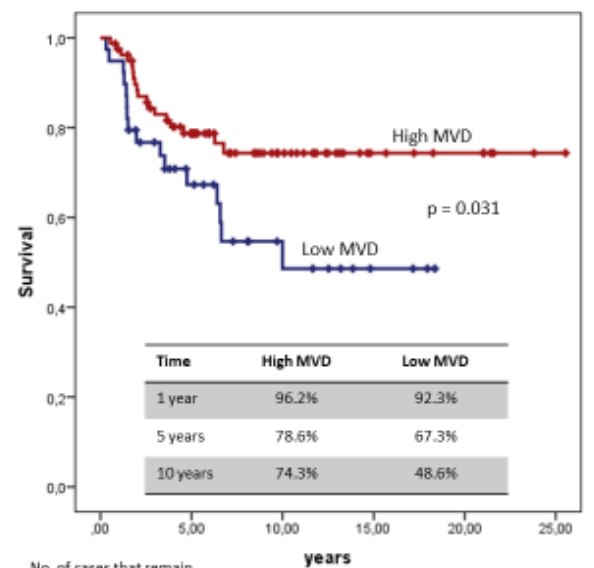

No. of cases that remain

High MVD $\quad 80 \quad 49 \quad 23$

$\begin{array}{lllllll}\text { LOW MVD } & 39 & 18 & 8 & 3 & 0 & 0\end{array}$

C

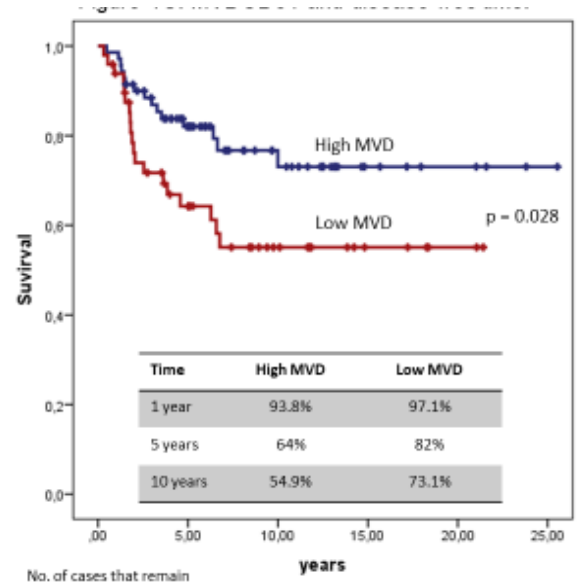

High MVD $\quad \begin{array}{llllll}49 & 25 & 12 & 5 & 2 & 0\end{array}$

$\begin{array}{lllllll}\text { Low MOV } & 70 & 43 & 20 & 7 & 4 & 1\end{array}$

E

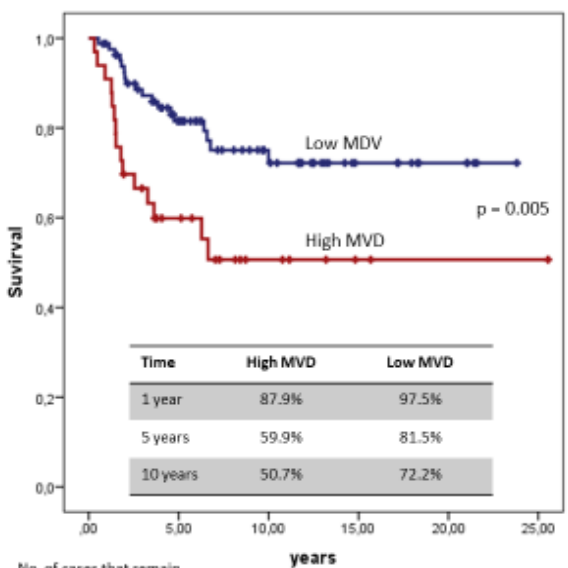

No. of cases that remsin

High MVD $33 \quad 15$

Low MOV $\quad 82 \quad 51$
B

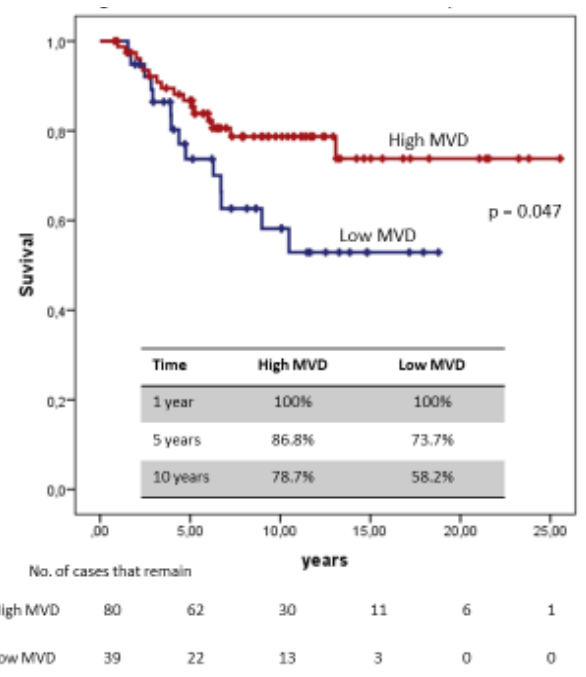

D

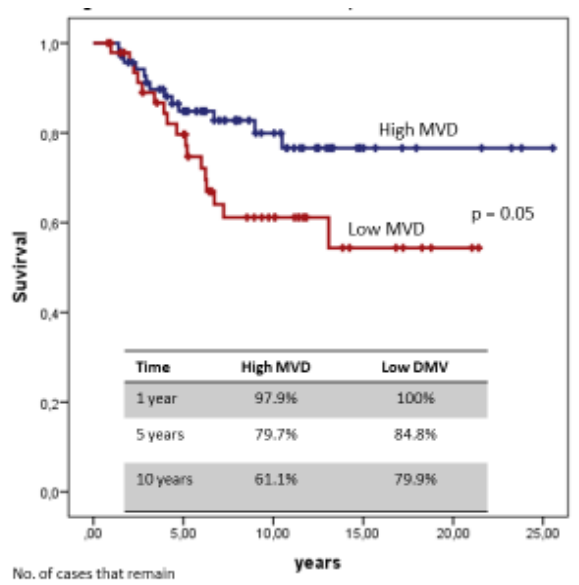

$\begin{array}{lllllll}\text { High MVD } & 49 & 33 & 16 & 6 & 2 & 0\end{array}$

$\begin{array}{llllll}\text { LOWMOV } & 70 & 50 & 25 & 7 & 4\end{array}$

$\mathbf{F}$

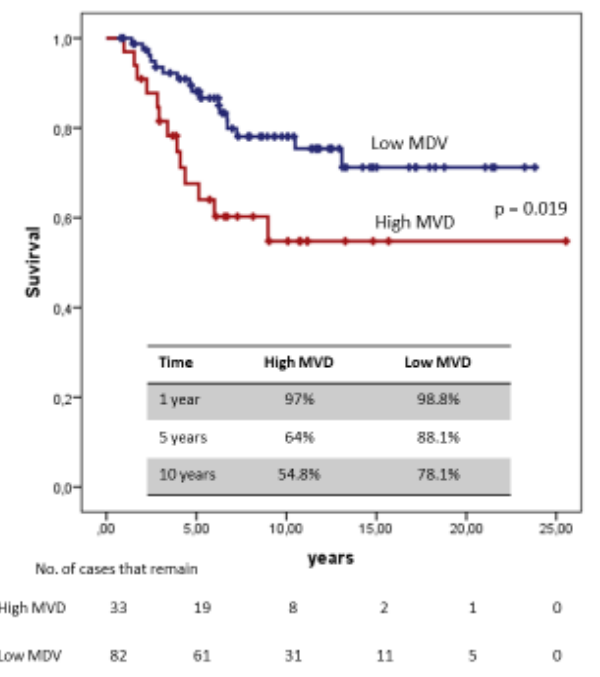

Figure 1. Survival curves. (A) MVDCD34 and disease-free time (B) MDVCD34 and survival specific cancer (C) MVDCD31 and disease-free time (D) MVDCD31 and cancer specific survival (E) MDVCD105 and disease-free time (F) MDVCD105 and specific cancer survival 

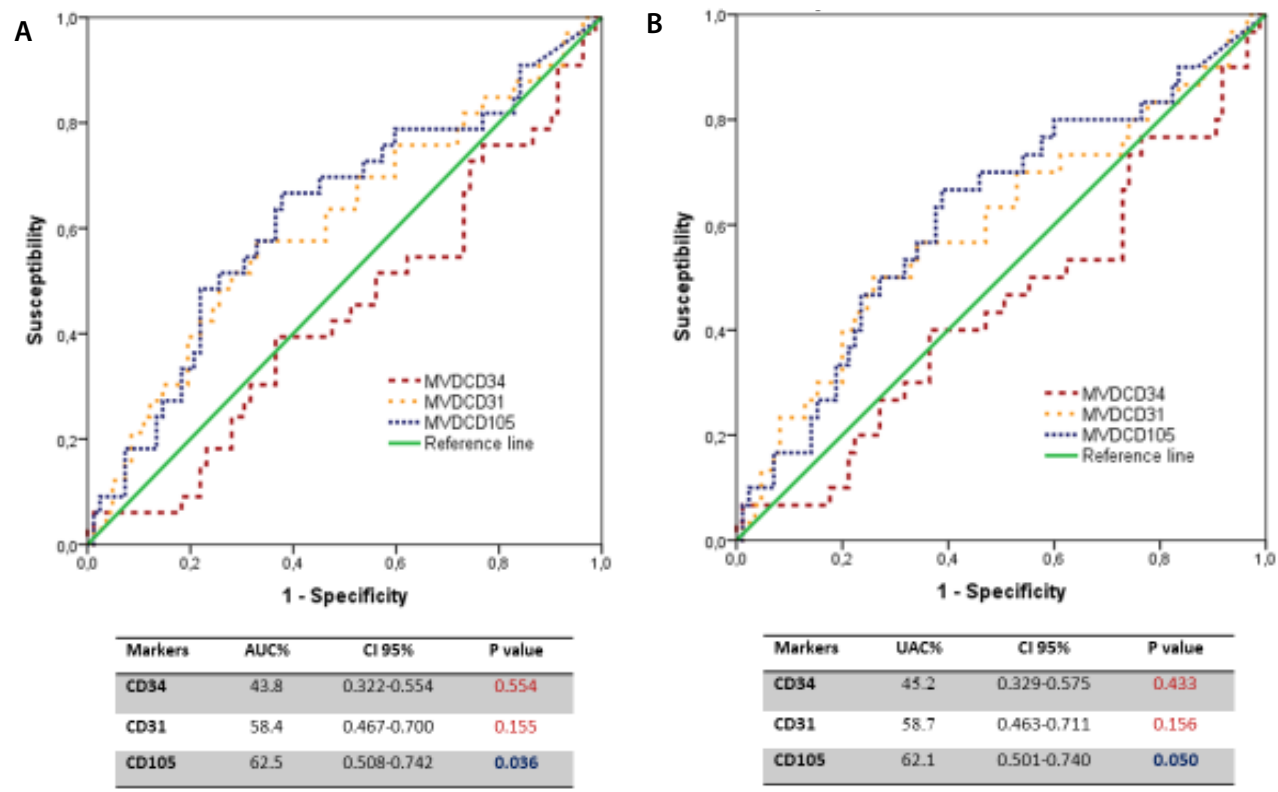

Figure 2. (A) ROC curves. Angiogenic markers and tumour recurrence (B) Angiogenic markers and cancer mortality

A

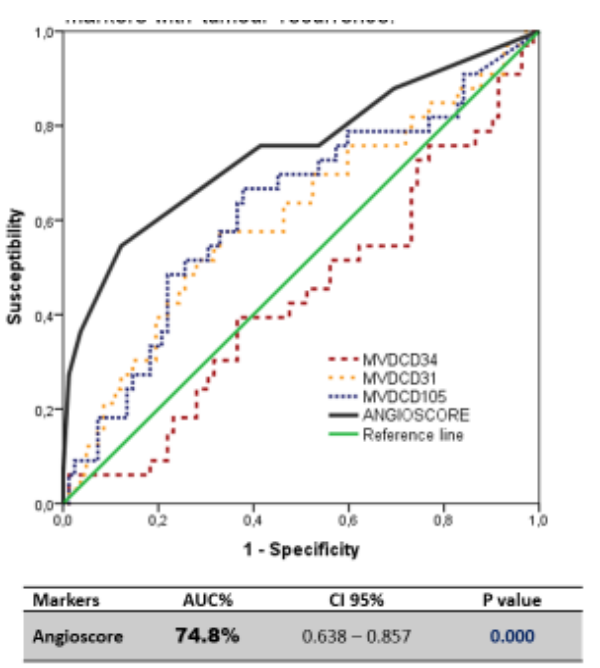

C

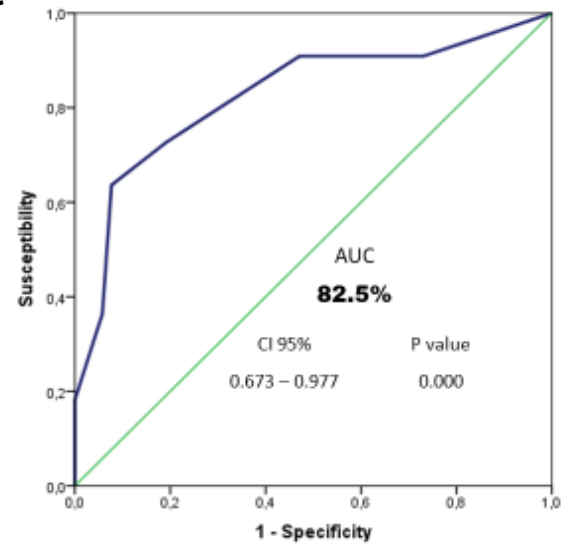

B

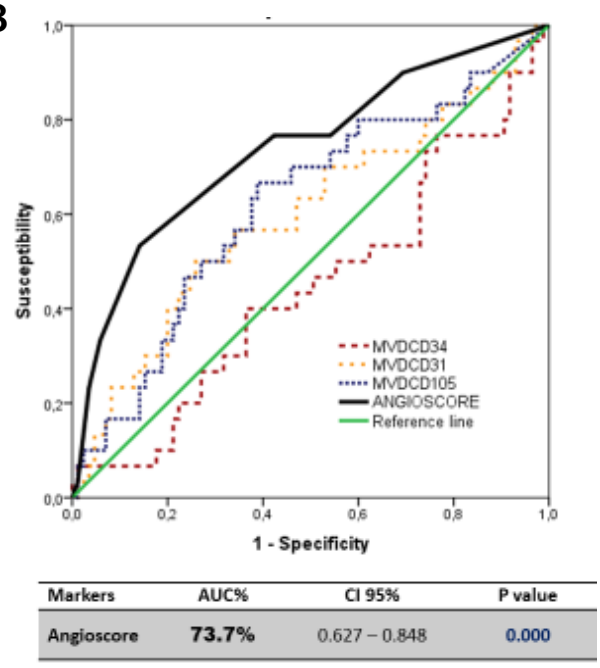

D

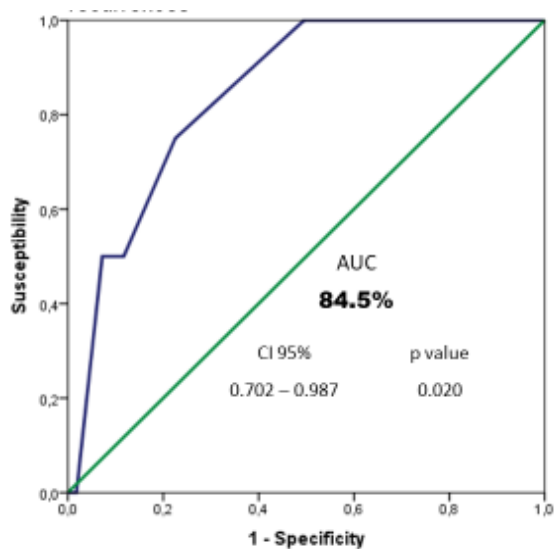

Figure 3. ROC curve. (A) "Angioscore" and endothelial markers with tumour recurrence (B) "Angioscore" and endothelial markers with cancer mortality (C) "Angioscore" with brain metastases (D) "Angioscore" with pulmonary recurrences 
Table 1. Clinical and pathological characteristics of the series

\begin{tabular}{|c|c|c|c|}
\hline & & N (119) & $\%$ \\
\hline Gender & $\begin{array}{l}\text { Women } \\
\text { Men }\end{array}$ & $\begin{array}{l}27 \\
92\end{array}$ & $\begin{array}{l}22.7 \\
77.3\end{array}$ \\
\hline Years & Mean (SD) & \multicolumn{2}{|c|}{$61.6(8.5)$} \\
\hline Smoking habit & $\begin{array}{l}\text { No smoker } \\
\text { Smoker } \\
\text { Former smoker }\end{array}$ & $\begin{array}{l}20 \\
66 \\
33\end{array}$ & $\begin{array}{l}16.8 \\
55.5 \\
27.7\end{array}$ \\
\hline Surgery & $\begin{array}{l}\text { Anatomical segmentectomy } \\
\text { Lobectomy } \\
\text { Pneumonectomy }\end{array}$ & $\begin{array}{c}7 \\
111 \\
1\end{array}$ & $\begin{array}{c}5.9 \\
93.3 \\
0.8\end{array}$ \\
\hline TNM (Stage) & $\begin{array}{l}\text { Tis }(0) \\
\text { T1a (IA1) } \\
\text { T1b (IA2) } \\
\text { T1c (IA3) }\end{array}$ & $\begin{array}{c}7 \\
23 \\
47 \\
42\end{array}$ & $\begin{array}{c}5.9 \\
19.3 \\
39.5 \\
35.3\end{array}$ \\
\hline Histological pattern & $\begin{array}{l}\text { Lepidic } \\
\text { Acinar } \\
\text { Papillary } \\
\text { Micropapillary } \\
\text { Solid }\end{array}$ & $\begin{array}{c}53 \\
101 \\
18 \\
12 \\
69 \\
\end{array}$ & $\begin{array}{c}44.5 \\
84.9 \\
15.1 \\
10.1 \\
58\end{array}$ \\
\hline Nuclear degree & $\begin{array}{l}1 \\
2 \\
3\end{array}$ & $\begin{array}{l}27 \\
76 \\
16\end{array}$ & $\begin{array}{l}22.7 \\
63.9 \\
13.4\end{array}$ \\
\hline Number of mitosis & Median (range) & \multicolumn{2}{|c|}{$6(59)$} \\
\hline Lymphatic invasion & & 29 & 24.4 \\
\hline Vascular invasion & & 30 & 25.2 \\
\hline Tumoural necrosis & & 62 & 52.1 \\
\hline Recurrence & $\begin{array}{l}\text { Local -regional } \\
\text { Metastasis }\end{array}$ & $\begin{array}{c}34 \\
7 \\
27\end{array}$ & $\begin{array}{c}28.6 \\
5.9 \\
22.6\end{array}$ \\
\hline Status & $\begin{array}{l}\text { Alive } \\
\text { Cancer mortality } \\
\text { Mortality by other causes } \\
\text { Second primary tumour }\end{array}$ & $\begin{array}{c}43 \\
30 \\
37 \\
9\end{array}$ & $\begin{array}{c}36.1 \\
25.2 \\
31.1 \\
7.6\end{array}$ \\
\hline
\end{tabular}

SD: Standard deviation, ADC: Adenocarcinoma, AIS: Adenocarcinoma In Situ, MIA: Minimally invasive ADC

Table 2. Multivariate analysis of CD34, CD31 and CD105 angiogenic markers

\begin{tabular}{|c|c|c|c|}
\hline & $\boldsymbol{\beta}$ & HR & CI 95\% \\
\hline CD34 & -1.256 & 0.285 & $0.131-0.620$ \\
\hline CD31 & 1.705 & 5.502 & 0.002 \\
\hline CD105 & 1.300 & 3.671 & 0.000 \\
\hline
\end{tabular}

Table 3. ROC analysis of the "Angioscore" and type of tumour recurrence (AUC: Area under the curve)

\begin{tabular}{|c|c|c|c|}
\hline Recurrence & AUC\% & 95\%CI & p value \\
\hline Pulmonary & 84.5 & $0.702-0.987$ \\
\hline Brain Metastasis & 82.5 & $0.673-0.977$ \\
\hline Local- Regional & 78.2 & $0.591-0.973$ \\
\hline Others & 46.8 & 0.000 \\
\hline
\end{tabular}

Curves were compared with the log-rank test. A significant difference in the prognosis of both groups was found (Figure 4).

The clinical and pathological variables and "Angioscore" were analysed as prognosis factors in a forward stepwise Cox multivariate regression model for DFS and CSS. The "Angioscore" was the only factor to enter the regression as an independent prognosis factor for DFS and SCS, with HR 5.748 (95\%CI: 5.878-11.481, p<0.001) and HR 5.169 (95\%CI: 2.507-10.657, p<0.001), respectively (Table 4).

\section{Discussion}

Lung cancer is a serious health problem with a very strong impact from both the healthcare and socio-economic points of view. The relapse rate in stage I NSCLC lies between $10 \%$ and $30 \%$ according to consulted authors [9-11]. In our series, $28.6 \%$ of the patients suffered relapse, of whom $70.6 \%$ had distance relapse, mainly in the brain, and $25.2 \%$ of them died from this disease.

In the present-day, a huge challenge lies in managing patients with pulmonary resection by NSCLC, that of developing new markers that can help to identify subjects at higher risk of recurrence and mortality.

This last point was the reason for this research, which included a series of 119 patients diagnosed with lung ADC classified in stage IA. The impact of tumour angiogenesis on DFS and CSS was analysed, along with other morphological factors, and a score was created. CD34 is a highly glycosylated transmembrane glycoprotein, [12] and the role of this marker as a prognosis factor in LC is controversial [1,3,12-14]. This work found an association between a low MVD-CD34 expression and worse results in these patients. Despite very few studies agreeing with these data, Pomme et al. [15] evaluated the expression of several 

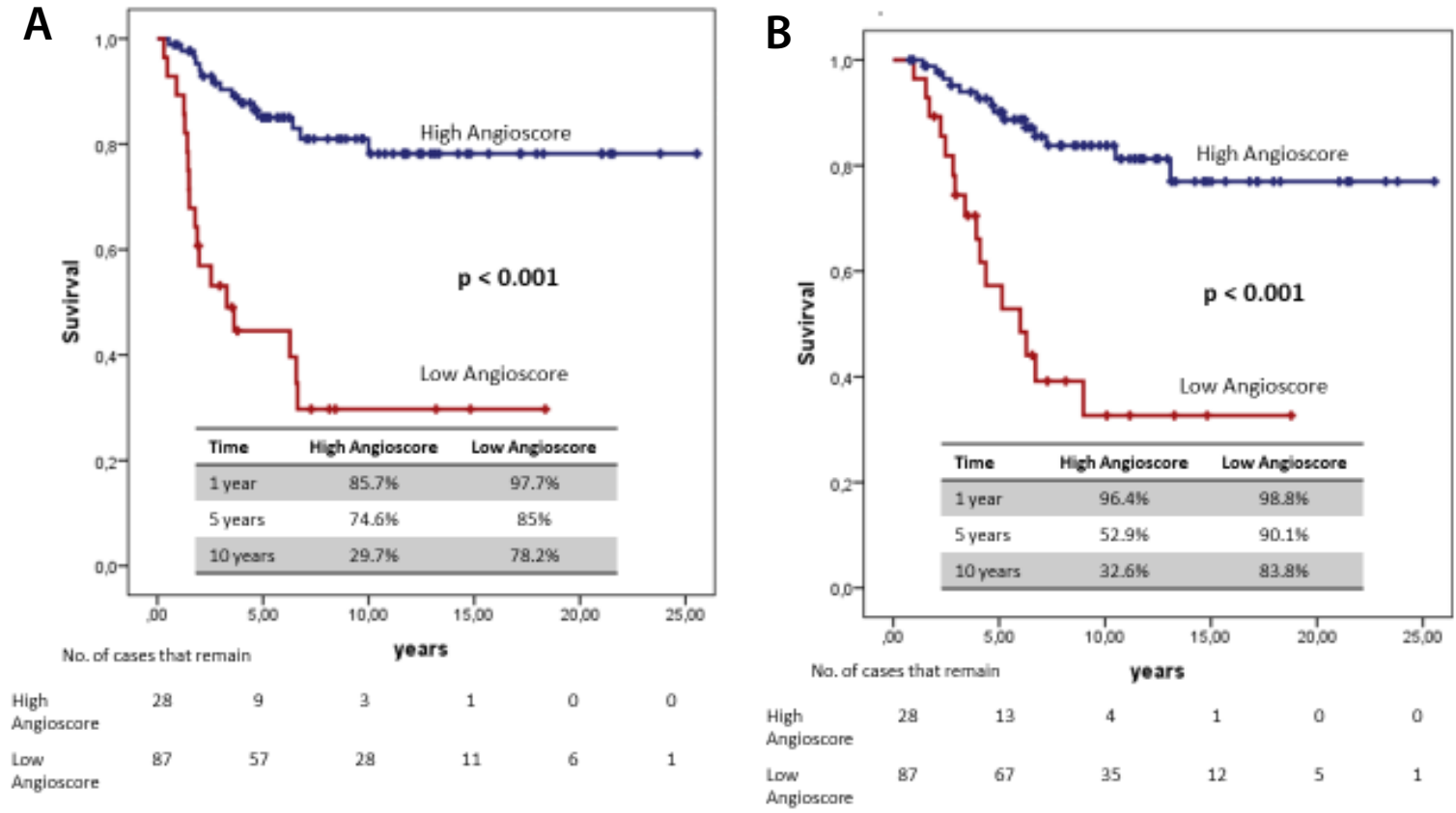

Figure 4. Survival curves (A) "Angioscore" and disease-free time (B) "Angioscore" and survival specific cancer

Table 4. Multivariate analysis between clinicopathological characteristics and angio score with DFS and CSS of the series

\begin{tabular}{|c|c|c|c|c|c|c|}
\hline \multirow[t]{2}{*}{ Variable } & \multicolumn{3}{|c|}{ DFS } & \multicolumn{3}{|c|}{ CSS } \\
\hline & HR & CI 95\% & p value & HR & CI 95\% & p value \\
\hline "Angioscore" & 5.748 & $2.878-11.481$ & 0.000 & 5.169 & $2.507-10.657$ & 0.000 \\
\hline \multicolumn{7}{|c|}{ Variables that are not in the equation } \\
\hline & \multicolumn{2}{|c|}{ score } & p value & \multicolumn{2}{|c|}{ score } & p value \\
\hline Micropapillary patterns & \multicolumn{2}{|c|}{2.737} & 0.098 & \multicolumn{2}{|c|}{2.701} & 0.100 \\
\hline Necrosis & \multicolumn{2}{|c|}{2.131} & 0.144 & \multicolumn{2}{|c|}{$2-014$} & 0.156 \\
\hline
\end{tabular}

markers related to tumoural angiogenesis in NSCLC. These authors found that MVD-CD34 < at $65 / \mathrm{mm} 2$ in the centre of the tumour was related to the worst prognosis. In a recent study, Xing et al. [16] related MVD-CD34 and blood flow with ultrasound (US) in lung tumour grafts in rabbits, and found a relation between higher MVD-CD34 and better survival. These contradictions have also been observed in clear cell renal carcinoma by Yildiz et al. [17] who found that high MVD-CD34 was related to "non-metastatic status, lack of microscopic vascular invasion, small tumour size and early tumour stage".

The reason why low MVD-CD34 expression is related to worse prognosis is not clear. Some authors have previously described how the lung vascular architecture is unique by demonstrating that bronchial carcinoma employs existing blood vessels [1]. Others have suggested a "non-angiogenic" growth pattern in LC [18], as in the liver, lymph glands [19] and lung metastases [20]. Moreover, as MVD in the lung is normally high, hypoxic tumour regions are rare and, therefore, the oxygen concentration needed to induce proangiogenic factors does not seem enough to stimulate the formation of new vessels, at least not in initial tumour stages [1].

CD31 is a cell surface molecule that has been proposed as a standard Immunohistochemistry marker to evaluate angiogenesis according to an international consensus about methodological criteria to assess MVD [2]. Contradictory results have been found in the literature, which are mentioned later [12,21-23].
In their large study conducted with 515 NSCLC patients, Pastorino et al. [21] found no relation to MVD-CD31 and these patients' prognosis. These authors pointed out that the angiogenic or "non-angiogenic" pattern was more significant than studying MVD. Nor did Duarte et al. [22] find an increase in MVD, but CD31 was associated with a worse prognosis. However, Koukourakis et al. [24] evaluated MVD-CD31 in tumour tissue and evidenced that high MVD was related to worse survival. Giatromanolaki et al. [25] conducted a study with 107 patients classified as T1-2N0-1M0, and related high MVD to a worse prognosis. This finding coincided with Kuang et al. [23] and Bacic et al. [4], who found that prognosis significance was more evident in those patients in advanced ADC stages.

The present study evidenced a marked relation between a worse prognosis of this disease and increased MVD-CD31. Nevertheless, an increase in MVD in lungs does not indicate greater angiogenic activity [24]. Hence the present study evaluated the expression of CD105, which is a marker of activated endothelial cells, a membrane glycoproteintype that binds to TGF $\beta 1$ and 3 [3]. It has also been studied as a marker of angiogenesis and a prognostic factor in many tumour types $[3,26,27]$.

A significant relation was found between high MVD-CD105 expression and a worse prognosis, with a higher relapse rate for this group of patients.

Mineo et al. [14] and Pomme et al. [15] also reported worse survival for patients with high MVDCD105. However, the multivariate analysis 
did not enter regression as an independent variable. MVDCD105 has been related to a bad prognosis factor in breast cancer [26,28], cancers of the digestion system, head/neck neoplasias [28] and LC [3,27,28].

In general terms, several research works have attempted to evaluate which markers better express a tumour's vascular status independently and its relation to patient outcomes. By means of a ROC curve, the present study evaluated in each angiogenesis marker the capacity to discriminate patients according to their outcomes. We found that these markers were not very exact at discerning the prognosis of patients with stage IA lung ADC for both relapse and specific cancer mortality. The AUCs for MVD-CD34 and MVD-CD31 were not statistically significant. However, AUC showed a significant level for MVD-CD105, but it was not very exact.

The weakness of these markers is basically due to tumoural vascularisation being much more complex and dynamic, where several proangiogenic factors participate, it is essentially where neoangiogenesis outbreaks appear, and it is not the only type of vascularisation used by tumours. Other widely studied vascularisation types in LC are the cooptation of host vessels accompanied by their vascular remodelling by apoptosis [18]. Thus, tumoural vasculogenesis has been demonstrated in the studies by Maeda et al. [13]. Finally, there is the vasculogenic mimicry observed by researchers like Kaessmeyer $e t$ al. [29]. Based on not only the poor exactness of the separately analysed endothelial markers to discriminate patients' prognoses, but also on the search for a better evaluation of a tumour's vascular status and its relation to patient evolution, a decision was made to create a scoring system called "Angioscore".

Former studies have used the combination of certain proangiogenic markers as a prognosis factor. Sanmartin et al. [30] found an association between a high VEGFA mRNA expression, a low VEGFB expression and D mRNA with worse patient evolution. Zhang et al. [31] identified that combining the mRNA VEGFA/FLT1/KDR expression was highly consistent as a prognosis factor in NSCLC, colon and brain cancer. However, the study populations in these works were highly heterogeneous in terms of clinical, pathological characteristics, treatment, and results.

The present work found that the ability of the "Angioscore" to discriminate between a patient with or without tumour relapse, and between those who had died or not by ADC, was $74.8 \%$ and $73.7 \%$, respectively. These values are much more accurate than when the analysis was done with each marker separately. Likewise, its discriminating capacity was estimated according to relapse type, with $84.5 \%$ for lung-related relapses and $82.5 \%$ for brain-related relapses.

The "Angioscore" allowed two patient groups to be obtained according to risk, with a statistically difference between them in DFS and CSS.

A Cox multivariate analysis was run to evaluate the "Angioscore" jointly with the morphological variables of ADC of our series. In this new analysis, the "Angioscore" was the only independent variable in patient evolution; that is, those patients with a high "Angioscore" were at an almost 5.75-fold higher risk of tumoural relapse and one of 5.17- fold of dying from this tumour type than those with a low "Angioscore".

Therefore, the data obtained with this study suggest that the "Angioscore" could be a useful tool because it acts as a prognosis factor in stage IA lung ADC at the expense of its clinical evaluation.

\section{Conclusion}

By way of conclusion, low MVD-CD34 is associated with a worse DFS and CSS but offers no predictive value for relapse and mortality. High MVD-CD31 is significantly related to low DFS and CSS, but the marker was not predictive of tumoural progression. High MVDCD105 is associated with worse clinical outcomes. Its predictive value is significant, but it acts as an inaccurate marker. Grouping endothelial cells surface markers by the "Angioscore" is a useful tool for evaluating the vascular status of patients with stage IA lung ADC. The "Angioscore" represents a more exact predictive value for relapses and death because it allows high- and low-risk groups to be classified. Finally, the "Angioscore" was the only independent prognosis factor of patients with stage IA lung ADC in our series.

\section{Acknowledgment}

This project is supported by the Spanish Thoracic Surgery Society (SECT) grant, prize awarded to first place of research project 2016.

We thank Dr. José Padilla Alarcón and Dr. Cristóbal Aguilar for their collaboration in the project.

\section{Conflict of interests}

The authors declare that there is no conflict of interest regarding the publication of this article.

\section{References}

1. Offersen B V, Pfeiffer P, Hamilton-Dutoit S, Overgaard J (2001) Patterns of angiogenesis in nonsmall-cell lung carcinoma. Cancer 91: 1500-1509.

2. Vermeulen P, Gasparini G, Fox S, Colpaert C, Marson L, et al. (2002) Second international consensus on the methodology and criteria of angiogenesis quantification in solid human tumours. Eur J Cancer 38: 1564-1579.

3. Tanaka F, Otake Y, Yanagihara K, Kawano Y, Miyahara R, et al. (2001) Evaluation of angiogenesis in non-small cell lung cancer: comparison between anti-CD34 antibody and anti-CD105 antibody. Clin Cancer Res 7: 3410-3415.

4. Bačić I, Karlo R, Zadro A, Zadro Z, Skitarelić N, et al. (2017) Tumor angiogenesis as an important prognostic factor in advanced non-small cell lung cancer (Stage IIIA). Oncol Lett 15: 2335-2339.

5. Siegel RL, Miller KD, Jemal A (2020) Cancer statistics, 2019. CA Cancer J Clin 69 7-34.

6. Travis WD, Brambilla E, Nicholson AG, Yatabe Y, Austin JHM, et al. (2015) The 2015 World Health Organization classification of lung tumors. Impact of genetic, clinical and radiologic advances since the 2004 classification. J Thorac Oncol 10: 1243-12460.

7. De Aguiar Quevedo K, Cruz Mokarrieta J, Cerón Navarro J, Mancheño Francha N, Jordá Aragón C, et al. (2019) Clinical and pathological factors in pathologic stage IA lung adenocarcinoma: relevance of the micropapillary pattern and tumor necrosis. Med Res Arch 7: 1-20.

8. Barletta JA, Yeap BY, Chirieac LR (2010) The prognostic significance of grading in lung adenocarcinoma. Cancer 116: 659-669.

9. Maeda R, Yoshida J, Ishii G, Hishida T, Nishimura M, et al. (2011) Risk factors for tumor recurrence in patients with early-stage (stage I and II) non-small cell lung cancer patient selection criteria for adjuvant chemotherapy according to the seventh edition TNM classification. Chest 140: 1494-1502.

10. Yang Y, Mao Y, Yang L, He J, Gao S, et al. (2017) Prognostic factors in curatively resected pathological stage I lung adenocarcinoma. J Thorac Dis 9: 5267-5277.

11. Villar Álvarez F, Muguruza Trueba I, Vicente Antunes SI (2016) Apuntes sobre recidivas y segundos tumores en el cáncer de pulmón. Arch Bronconeumol 52: 545-546.

12. Meert AP, Paesmans M, Martin B, Delmotte P, Berghmans T, et al. (2002) The role of microvessel density on the survival of patients with lung cancer: a systematic review of the literature with meta-analysis. Br J Cancer 87: 694-701. 
13. Maeda R, Ishii G, Ito M, Hishida T, Yoshida J, et al. (2012) Number of circulating endothelial progenitor cells and intratumoral microvessel density in non- small cell lung cancer patients. Differences in angiogenic status between adenocarcinoma histologic subtypes. J Thorac Oncol 7: 503-511.

14. Mineo TC, Ambrogi V, Baldi a, Rabitti C, Bollero P, et al. (2004) Prognostic impact of VEGF, CD31, CD34, and CD105 expression and tumour vessel invasion after radical surgery for IB-IIA non-small cell lung cancer. J Clin Pathol 57: 591-597.

15. Pomme G, Augustin F, Fiegl M, Droeser RA, Sterlacci W, et al. (2015) Detailed assessment of microvasculature markers in non-small cell lung cancer reveals potentially clinically relevant characteristics. Virchows Arch 467: 55-66.

16. Xing J, He W, Ding YW, Li Y, Li YD, et al. (2018) Correlation between contrastenhanced ultrasound and microvessel density via CD31 and CD34 in a rabbit VX2 lung peripheral tumor model. Med Ultrason 1: 37

17. Yildiz E, Ayan S, Goze F, Gokce G, Gultekin EY, et al. (2007) Relation of microvessel density with microvascular invasion, metastasis and prognosis in renal cell carcinoma BJU Int 101: 758-764.

18. Donnem T, Reynolds AR, Kuczynski EA, Gatter K, Vermeulen PB, et al. (2018) Nonangiogenic tumours and their influence on cancer biology. Nat Rev Cancer 18: 323-326.

19. Vermeulen PB, Sardari Nia P, Colpaert C, Dirix LY, Van Marck E, et al. (2002) Lack of angiogenesis in lymph node metastases of carcinomas is growth pattern-dependent. Histopathology 40: 105-107.

20. Pezzella F, Manzotti M, Di Bacco A, Viale G, Nicholson AG, et al. (2000) Evidence for novel non-angiogenic pathway in breast-cancer metastasis. Lancet 355: 1787-1788.

21. Pastorino U, Andreola S, Tagliabue E, Pezzella F, Incarbone M, et al. (1997) Immunocytochemical markers in stage I lung cancer: relevance to prognosis. $J$ Clin Oncol 15: 2858-2865.

22. Duarte IG, Bufkin BL, Pennington MF, Gal AA, Cohen C, et al. (2011) Angiogenesis as a predictor of survival after surgical resection for stage I non-small- cell lung cancer. Gen Thorac Surg 115: 652-659.
23. Kuang BH, Wen XZ, Ding Y, Peng RQ, Cai PQ, et al. (2013) The prognostic value of platelet endothelial cell adhesion molecule-1 in non-small-cell lung cancer patients. Med Oncol 30: 536.

24. Koukourakis MI, Giatromanolaki A, Thorpe PE, Brekken RA, Sivridis E, et al. (2000) Vascular endothelial growth factor/KDR activated microvessel density versus CD31 standard microvessel density in non-small cell lung cancer. Cancer Res 60: 3088-3095.

25. Giatromanolaki A, Koukourakis M, O’Byrne K, Fox S, Whitehouse R, et al. (1996) Prognostic value of angiogenesis in operable non-small cell lung cancer. J Pathol 179: 80-88.

26. Kumar S, Ghellal A, Li C, Byrne G, Haboubi N, et al. (1999) Breast carcinoma: vascular density determined using CD105 antibody correlates with tumor prognosis Cancer Res 59: 856-861.

27. Medetoglu B, Gunluoglu MZ, Demir A, Melek H, Buyukpinarbasili N, et al. (2010) Tumor angiogenesis in predicting the survival of patients with stage I lung cancer. $J$ Thorac Cardiovasc Surg 140: 996-1000.

28. Zhang J, Zhang L, Lin Q, Ren W, Xu G, et al. (2018) Prognostic value of endoglinassessed microvessel density in cancer patients: a systematic review and meta-analysis. Oncotarget 9: 7660-7671.

29. Kaessmeyer S, Bhoola K, Baltic S, Thompson P, Plendl J, et al. (2014) Lung cancer neovascularisation: cellular and molecular interaction between endothelial and lung cancer cells. Immunobiology 219: 308-314.

30. Sanmartín E, Sirera R, Usó M, Blasco A, Gallach S, et al. (2014) A gene signature combining the tissue expression of three angiogenic factors is a prognostic marker in early-stage non-small cell lung cancer. Ann Surg Oncol 21: 612-620.

31. Zhang SD, Leung KL, McCrudden CM, Kwok HF (2015) The prognostic significance of combining VEGFA, FLT1 and KDR mRNA expressions in brain tumors. $J$ Cancer 6: $812-818$.

Copyright: (C2020 De Aguiar-Quevedo K. This is an open-access article distributed under the terms of the Creative Commons Attribution License, which permits unrestricted use, distribution, and reproduction in any medium, provided the original author and source are credited. 